Prions (2nd, revised and extended edition) 


\section{Contributions to Microbiology}

\section{Vol. 11}

Series Editors

Axel Schmidt Wuppertal

Heiko Herwald Lund 


\section{Prions}

A Challenge for Science, Medicine and the Public Health System 2nd, revised and extended edition

Volume Editors

Holger F. Rabenau Frankfurt/Main

Jindrich Cinatl Frankfurt/Main

Hans Wilhelm Doerr Frankfurt/Main

26 figures, 2 in color, and 19 tables, 2004

\footnotetext{
KARGER $\quad \begin{aligned} & \text { Basel } \cdot \text { Freiburg } \cdot \text { Paris } \cdot \text { London } \cdot \text { New York } \cdot \\ & \text { Bangalore } \cdot \text { Bangkok } \cdot \text { Singapore } \cdot \text { Tokyo } \cdot \text { Sydney }\end{aligned}$
} 


\title{
Contributions to Microbiology
}

formerly 'Concepts in Immunopathology' and

'Contributions to Microbiology and Immunology'

Prof. Dr. Holger F. Rabenau
Institut für Medizinische Virologie
der Universität Frankfurt/Main
Paul-Ehrlich-Strasse 40
D-60596 Frankfurt/Main (Germany)

\section{Dr. Jindrich Cinatl}

Institut für Medizinische Virologie

der Universität Frankfurt/Main

Paul-Ehrlich-Strasse 40

D-60596 Frankfurt/Main (Germany)

\author{
Prof. Hans Wilhelm Doerr \\ Institut für Medizinische Virologie \\ der Universität Frankfurt/Main \\ Paul-Ehrlich-Strasse 40 \\ D-60596 Frankfurt/Main (Germany)
}

\author{
Library of Congress Cataloging-in-Publication Data \\ Prions : a challenge for science, medicine, and the public health system / volume editors, H.F. \\ Rabenau, J. Cinatl, H.W. Doerr. - 2nd, rev. and ext. ed. \\ p. cm. - (Contributions to microbiology ; v. 11) \\ Includes bibliographical references and index. \\ ISBN 3-8055-7656-0 \\ 1. Prion diseases. 2. Prions. I. Rabenau, Holger F. II. Cinatl, Jindrich. III. Doerr, Hans \\ Wilhelm. IV. Series.
}

QR201.P737P756 2003

$616.8^{\prime} 3-\mathrm{dc} 22$

Bibliographic Indices. This publication is listed in bibliographic services, including Current Contents ${ }^{\circledR}$ and Index Medicus.

Drug Dosage. The authors and the publisher have exerted every effort to ensure that drug selection and dosage set forth in this text are in accord with current recommendations and practice at the time of publication. However, in view of ongoing research, changes in government regulations, and the constant flow of information relating to drug therapy and drug reactions, the reader is urged to check the package insert for each drug for any change in indications and dosage and for added warnings and precautions. This is particularly important when the recommended agent is a new and/or infrequently employed drug.

All rights reserved. No part of this publication may be translated into other languages, reproduced or utilized in any form or by any means electronic or mechanical, including photocopying, recording, microcopying, or by any information storage and retrieval system, without permission in writing from the publisher.

(C) Copyright 2004 by S. Karger AG, P.O. Box, CH-4009 Basel (Switzerland)

www.karger.com

Printed in Switzerland on acid-free paper by Reinhardt Druck, Basel

ISSN $1420-9519$

ISBN 3-8055-7656-0 


\section{Contents}

VII Dedication in Remembrance of Andreas Scheid (1941-2001)

Schmidt, A. (Wuppertal)

\section{Note of the Series Editor}

Schmidt, A. (Wuppertal)

IX Preface to the Second Edition

Rabenau, H.F.; Cinatl, J.; Doerr, H.W. (Frankfurt/Main)

X Preface to the First Edition

Rabenau, H.F.; Cinatl, J.; Doerr, H.W. (Frankfurt/Main)

1 Transmissible Spongiform Encephalopathies: The Prion Theory Background and Basic Information

Riesner, D. (Düsseldorf)

14 Structural Biology of Prions

Cappai, R. (Melbourne/Parkville); Collins, S.J. (Parkville)

33 Prion Strains and Species Barriers

Hill, A.F.; Collinge, J. (London)

50 Prions of Saccharomyces and Podospora

Baxa, U.; Taylor, K.L.; Steven, A.C.; Wickner, R.B. (Bethesda, Md.)

72 Human Prion Diseases: Cause, Clinical and Diagnostic Aspects

Knight, R. (Edinburgh); Brazier, M.; Collins, S.J. (Parkville) 
98 Epidemiology and Risk Factors of Transmissible Spongiform Encephalopathies in Man

Zerr, I.; Poser, S. (Göttingen)

117 Aspects of Risk Assessment and Risk Management of Nosocomial Transmission of Classical and Variant Creutzfeldt-Jakob Disease with Special Attention to German Regulations

Beekes, M.; Mielke, M.; Pauli, G.; Baier, M.; Kurth, R. (Berlin)

136 Resistance of Transmissible Spongiform Encephalopathy Agents to Decontamination

Taylor, D.M. (Edinburgh)

146 Bovine Spongiform Encephalopathy and Its Relationship to the Variant Form of Creutzfeldt-Jakob Disease

Bradley, R. (Guildford)

186 Possibilities to Manage the BSE Epidemic: Cohort Culling versus Herd Culling - Experiences in Switzerland Heim, D.; Murray, N. (Liebefeld)

193 Regulatory Aspects of BSE and CJD with Special Emphasis on Germany von Rheinbaben, F.; Schmidt, A. (Witten/Herdecke)

208 The Challenge for the Public Health System Minor, P.D. (Potters Bar)

216 Author Index

217 Subject Index 


\section{Dedication in Remembrance of Andreas Scheid (1941-2001)}

Andreas Scheid, PhD, MD, University Professor, virologist and physician, was an outstanding scientist in influenza research at Rockefeller University, USA, and later on the Director and Head of the Institute of Medical Virology at the Heinrich Heine University of Düsseldorf, Germany. He also had a lot of interests, especially in cultural aspects, such as being an dedicated musician.

Andreas, you left us far too early due to a severe, very long-lasting and painful disease. I am very indebted to you as my personal teacher in virology. You gave me a lot of advice in virology, especially in our exchanges from physician to physician and as a personal friend.

Axel Schmidt

Series Editor 


\section{Note of the Series Editor}

New emerging pathogens and/or infectious agents are a main scope of the Karger book series Contributions to Microbiology.

Prion-associated diseases such as BSE and other spongiform encephalopathies are a major and worldwide focus of interest at the moment, ranging from sciences, over politics and public media, to the 'worried' consumer of meat and meat-associated products, as probably the majority of us are.

I would like to express my special thanks to the highly competent and experienced volume editors Holger F. Rabenau, Jindrich Cinatl and Hans Wilhelm Doerr, all at the Institute of Medical Virology, Johann Wolfgang von Goethe University, Frankfurt am Main, Germany, who already edited the first and extremely successful 7th volume of Contributions to Microbiology, published in 2001. They convinced and engaged outstanding and internationally recognised scientists and experts in the corresponding fields to contribute excellent chapters for the present volume. Due to the tremendous success and acceptance of the initial exciting volume of Contributions to Microbiology, the preparation of a second, completely revised, updated and extended edition became mandatory. Again to the editors: my personal thanks to you for once more taking on this new challenge. Moreover, I also personally thank Karger Publishers for their kind and very supportive and professional collaboration with the project.

This edition of the volume provides a very comprehensive and updated source of information on all aspects of prions and prion-associated diseases that has been derived from very different viewpoints concerning spongiform encephalopathies. Many novel and 'up-to-date' aspects are presented which have not been included in other textbooks so far and in such a comprehensive way, which in turn will inevitably lead to a higher and more sophisticated awareness of the present situation concerning the 'prion problem'.

Axel Schmidt, Series Editor

Witten/Herdecke, November 2003 


\section{Preface to the Second Edition}

This book was initiated and edited by general microbiologists or virologists, who had numerous questions concerning prion origin and replication, virulence and pathogenicity, diagnosis and therapy, transmission and susceptibility, as well as inactivation and prevention. Although the rapid progress of research had outdated the 'state of the art' at the time of publication, those questions were of such common interest that the book was soon sold out. Now, three years later, a second approach to these issues is presented. The protein-only hypothesis on prions is now commonly accepted, although there are some reservations. Therefore, the contribution dealing with arguments against this hypothesis was not rewritten. While the BSE epidemic has declined, the number of new, i.e. variant CreutzfeldtJacob disease cases has risen. Although it will probably not reach the features of an epidemic in humans, the challenge for science, medicine and public health is always present. After the first American case of BSE emerged in a cow that had not been imported, the question about an endogenous or exogenous origin of disease has again been raised. Our knowledge of prion biology has considerably improved covering both human, animal and even microbe affections. Beside some insights in basic research, the second edition emphasizes practical aspects of fighting human and animal prion diseases. Additionally, chapters on public regulations of this issue and on veterinary measures were included. The volume editors wish to thank Karger Publishers and the series editor of Contributions to Microbiology for encouraging this second edition. 


\section{Preface to the First Edition}

After the great successes of modern hygiene and medical microbiology, many people thought the threat of infectious diseases had disappeared. However, emerging and re-emerging infections with more or less pathogenic potential disproved this opinion. The onset of the AIDS epidemic has brought the old problem of slow virus diseases to general attention. For many years, it had been postulated that some of those diseases, particularly of the brain, were caused by unconventional viruses. Infections with these agents do not induce classical inflammations - acute or chronic encephalitis due to a specific immune reaction - but a slow and irreversible degeneration of the central nervous system presenting as encephalopathy. Those diseases had been considered rare events in animals and humans, only interesting medical and veterinary doctors and scientists - scrapie in sheep and Creutzfeldt-Jakob disease (CJD) in man were known only to specialists. The onset of the bovine spongiform encephalopathy (BSE) epidemic in Great Britain completely changed the situation. The fatal risk of consuming contaminated beef became a topic. And indeed, the fears were materialized when the first cases of new variant CJD (vCJD) were identified.

From the scientific point of view, it was a real sensation, when infectious agents without any nucleic-acid-based genome were hypothesized, which were later called proteinaceous infectious organisms (prions). The dogma that self-replicating biologic agents depend on genomic information conserved in the sequence of nucleic acids had to be given up. However, it should not be forgotten that prions are real 'viruses' (in the original sense of toxic material), 
as defined by the very early virologists. A lot of questions arose: How do those agents replicate? Do they always harm the host? Which factors of virulence can be identified? What are the mechanisms of pathogenicity? How are the agents transmitted? What are the options of early laboratory diagnosis and development of therapy and prevention?

In this edition of Contributions to Microbiology, leading scientists in different fields of biomedical research show once again how important it is to deal with the prion 'problem' in a multidisciplinary manner. The long-lasting discussion about the virus or prion theory is getting a clearer background. Furthermore, the structures of prions and their molecular biological analysis, and the questions of strain variations and species barrier are discussed. Another chapter tells us what we can learn about prions from yeast experiments. The possibilities of inactivation and disinfection of prions are of great importance for public health. This includes the test methods and their problems as well as the recommendations for clinical use and official regulations.

Another part of this book concentrates on the causes and clinical diagnostic aspects of TSE. While previously vCJD could be diagnosed only postmortem, new tests now allow identification of the disease with some confidence while victims are still alive (at least 1 year before its clinical onset). The tests include tonsil and appendix biopsies and magnetic resonance imaging. Furthermore, the epidemiology of human and animal prion diseases, disease management and the risks to public health or biologists (e.g. in the pharmaceutical industry) are also discussed.

In summary, this book informs about the state of the art of prion infection and disease.

Frankfurt/Main, May 2000

Holger F. Rabenau

Jindrich Cinatl

Hans Wilhelm Doerr 